\title{
The right to ignore: An epistemic defense of the nature/culture divide
}

\author{
Maria Kronfeldner \\ kronfeldnerm@ceu.edu
}

Penultimate draft. Published in: Joyce, R. 2017. Handbook of Evolution and Philosophy, Ch. 15, pp. 210-224, Routledge Chapman \& Hall, Incorporated. Please refer to published version for quotations and page numbers etc. This is for personal use only.

\begin{abstract}
This paper addresses whether the often-bemoaned loss of unity of knowledge about humans, which results from the disciplinary fragmentation of science, is something to be overcome. The fragmentation of being human rests on a couple of distinctions, such as the nature-culture divide. Since antiquity the distinction between nature (roughly, what we inherit biologically) and culture (roughly, what is acquired by social interaction) has been a commonplace in science and society. Recently, the nature/culture divide has come under attack in various ways, in philosophy as well as in cultural anthropology. Regarding the latter, for instance, the divide was quintessential in its beginnings as an academic discipline, when Alfred L. Kroeber, one of the first professional anthropologists in the US, rallied for (what I call) the right to ignore - in his case, human nature - by adopting a separationist epistemic stance. A separationist stance will be understood as an epistemic research heuristic that defends the right to ignore a specific phenomenon (e.g., human nature) or a specific causal factor in an explanation typical for a disciplinary field. I will use Kroeber's case as an example for making a general point against a bias towards integration (synthesis bias, as I call it) that is exemplified, for instance, by defenders of evolutionary psychology. I will claim that, in principle, a separationist stance is as good as an integrationist stance since both can be equally fruitful. With this argument from fruitful separation in place, not just the separationist stance but also the nature/culture divide can be defended against its critics.
\end{abstract}




\section{The epistemic fragmentation of the human}

If we are lucky, we experience ourselves as a unity - as human beings. Yet, the moment in which the phenomenon of "being human" is transferred to science, this unity gets lost. In the disciplinary differentiated science of today, this unity has no home. As an epistemic object (i.e., an entity studied by sciences) human beings get lost. They literally disappear on their way to science. The phenomenon of "being human" becomes cut into pieces, apportioned, fragmented-into an evolved human nature, a culture, an immune system, a neuronal system, a mind, a society, etc. Through this epistemic fragmentation (as I call it) humans become epistemically "available" for science, but not as humans. In this sense, there is no unitary account of being human, no anthropology in the all-inclusive sense, no simple answer to what it means to be human in contemporary science. Evolutionary thinking, anthropology, sociology, psychology, history, philosophy, etc.-provide separate fragments of knowledge about humans, with often complex relations among the fragments.

This epistemic fragmentation of the human has often been judged negatively, first and foremost for existential and metaphysical reasons. What is lost is a unitary Menschenbild, a meaningful picture of (and vision for) humans. Such a unified picture of being human would provide an ultimate answer to who and how we are (and should be), a picture that would have to be synthesized out of the bits and pieces offered by the multitude of sciences, even if it would simultaneously transcend the bits and pieces by its existential or metaphysical orientation. Secondly, independent of the need that some might still feel for an existential or metaphysical vision for being human, the fragmentation of "being human" can be criticized on the basis of epistemic reasons, namely by stressing that it prevents us from gaining valuable scientific knowledge about humans (Menschenkenntnis). This epistemic issue is the subject of this chapter. ${ }^{1}$

Mary Midgley (1995: xxv-xxvi), for instance, in her introduction to a new edition of her Beast and Man (1978), deplores the "sharp division[s] between mind and body, between culture and nature, between thought and feeling." According to her, these conceptual splits are "the bad side of our inheritance from the Age of Reason" and the foundation for the epistemic fragmentation of the human. She writes:

In modern times, science, because of its tremendous prestige, has been invoked to dramatize all these splits in a way that often has little to do with

${ }^{1}$ I take the distinction between view/knowledge (Menschenbild/Menschenkenntnis) from Mühlmann (1986 [1948]: 140). See Birken-Bertsch (2013) for the issue about losing a unified picture of being human. This paper is based on ideas first presented in Kronfeldner (2010) and Kronfeldner (2013). 
any real scientific work, but that seems to bring an unanswerable authority to the side that can exploit it. This ... adds a damaging warfare between the "two cultures" to the general chaos, deepening the gaps already opened by specialization between different studies and generally fragmenting the intellectual scene in a way that wastes endless time and resources. (ibid.)

For Midgley, the gaps she mentions are unquestionably negative-because of the motivation for them and because of their consequences for producing knowledge about humans. Conceptual dichotomies such as the nature/culture divide are bad since they have to do with claiming authority (for detail, see Kronfeldner forthcoming) and because they lead to a waste of time and resources. In a similar vein, Clifford Geertz, in a famous paper "The impact of the concept of culture on the concept of man," criticized, in the name of a "synthetic view," what he calls "the "stratigraphic" conception of the relations between biological, psychological, social, and cultural factors in human life." He writes:

In this [stratigraphic, MK] conception, man is a composite of "levels," each superimposed upon those beneath it and underpinning those above it. As one analyzes man, one peels off layer after layer, each such layer being complete and irreducible in itself, revealing another, quite different sort of layer underneath. (Geertz 1973: 37)

Like Midgley, Geertz mentions the quest for disciplinary autonomy and authority as reason for the attractiveness of the stratigraphic view. Both critics focus on the divide having a pragmatic function as a symbolic autonomy and authority securing device between scientific fields or disciplines, a function Kronfeldner (forthc) calls epistemic demarcation, and both regard the consequences as detrimental.

Ontologically the nature/culture divide can be justified, despite critique, be it from Midgley, Geertz or from developmental systems theory. It can be defended since there are differences among developmental resources in the world that allow us to successfully use the nature-culture divide to denote two different kinds of developmental resources traveling over time in distinct channels of inheritance. In the following, I thus assume that the nature/culture divide is ontologically meaningful. ${ }^{2}$ What I aim to defend here is that the

2 A detailed defense of this has to wait for another occasion. 
nature/culture divide can also be epistemically useful. ${ }^{3}$ To do so, I will use the example of Alfred L. Kroeber, student of Franz Boas, who hardened the natureculture divide to have the right to ignore one side of it, namely nature. According to him, nature and culture are separate evolutionary processes. Because of that, the cultural anthropologist can safely ignore nature. Kroeber had, I will claim, epistemically the right to ignore nature since to do so was epistemically fruitful. ${ }^{4}$

The argument is roughly the following: First and foremost, Midgley and Geertz forget that (whatever the motivations of those using it) the divide was fruitful in establishing and keeping an autonomous cultural anthropology alive, the very perspective from which they criticize the divide. Second, they seem to implicitly or explicitly not allow for a separationist stance-the right to ignore - as an epistemically fruitful research strategy, a heuristic. Interestingly, they share this with their most ardent contemporary critics, namely evolutionary psychologists, who challenge the autonomy of cultural anthropology (and other social sciences and humanities). Evolutionary psychologists do the latter by arguing for unity, i.e., an integration of knowledge about humans, to overcome the epistemic fragmentation of being human. As part of this call for integration, they despise social scientists who (like Kroeber) take a separationist stance.

In the following section, I shall illustrate the evolutionary psychologist's argument from integration against what these call the standard social science model, i.e., any model that entails claims towards the autonomy of social sciences on the basis of the separation of nature from culture (and society). I will reply with an argument from fruitful epistemic separation.

\section{The argument from integration}

Outlining why social scientists should pay attention to the insights of evolutionary psychology, Jerome Barkow, Leda Cosmides, and John Tooby write:

Conceptual integration generates this powerful growth in knowledge because it allows investigators to use knowledge developed in other disciplines to solve problems in their own. ... At present, crossing such

\footnotetext{
3 Some critics of the divide mention that pragmatically it can be useful; for example, Tim Lewens (2015: 91-2). Yet, even Lewens does not spell out the ontology that allows the pragmatic use in detail nor describe the details of the pragmatic use.

${ }^{4}$ I use the term "the right to ignore" in analogy to William James' (1897) appeal to a "right to believe."
} 
boundaries is often met with xenophobia, packaged in the form of such familiar accusations as "intellectual imperialism" or "reductionism." But by calling for conceptual integration in the behavioral and social sciences we are neither calling for reductionism nor for the conquest and assimilation of one field by another. ... Conceptual integration simply involves learning to accept with grace the irreplaceable intellectual gifts offered by other fields. To do this, one must accept the tenet of mutual consistency among disciplines, with its allied recognition that there are causal links between them. Compatibility is a misleadingly modest requirement, however for it is an absolute one. Consequently, accepting these gifts is not always easy, because other fields may indeed bring the unwelcome news that favored theories have problems that require reformulation. (Barkow et al. 1992: 12-13)

Nobody involved in serious contemporary scholarly debates about evolution and culture asks for any kind of reductionism that would involve giving up the disciplinary structure of science and the pluralism that follows from that (compatible but incongruent perspectives), not even evolutionary psychologists, at least not Barkow et al. (1992), it seems. The disciplinary structure of science is a bulwark against any call for imperialist unification via ontological, theoretical, or methodological reduction of social sciences to biological ones. ${ }^{5}$

Barkow et al. do not ask for any of these kinds of reductions or for imperialism; they ask for corrective integration, which is a process (and research strategy) of creating or checking for external consistency, consistency between one's own theory and fields external to one's own. One should note that integration is less global than unity since the perspectives or fields which are integrated stay separate and are not reduced, but they are integrated, connected, and consequently constrain each other. The constraining or correction can have a direction. When we check whether a theory from one field of studies is consistent with a theory from another field, and then adapt the one according to its conflicts with the other, then we integrate the corrected theory to the correcting theory. Thus integration can have a direction of adaptation. In effect, Barkow et al. ask cultural anthropologists to make sure that what they claim is consistent with well-established knowledge from evolutionary theory, while considering their version of evolutionary psychology as providing the new "irreplaceable intellectual gifts" to be taken into account.

Interestingly, at least in the quote from above, this corrective consistencychecking integration goes vice versa (i.e., the corrective direction goes both ways). Barkow et al. do not assume a corrective asymmetry between disciplines;

\footnotetext{
${ }^{5}$ See Mäki (2014) on what imperialism in these contexts can mean.
} 
they ask for corrective symmetry, for mutual integration. 6 Corrective asymmetry would mean: while the historian, sociologist or anthropologist will have to correct her theories when these conflict with evolutionary theory, the biologist does not have to correct anything just because a social scientist finds out something about this or that behavior that conflicts with evolutionary theory. And why is that, one might ask? "Because biology is more fundamental, more general," or so the argument might go. Claims for a corrective asymmetry probably rest on an implicit hierarchical ordering of scientific disciplines, from physics, to chemistry, to biological sciences, to psychology, to social sciences an ordering that is often derived from a so-called layer-cake model of reality (often associated with Oppenheim \& Putnam 1958). I am no fan of a corrective asymmetry between disciplines, but will not develop an argument against it here. ${ }^{7}$ The focus shall rather be on the value of integration. My argument against the value of integration holds even if there were corrective asymmetries between disciplines.

The reason integration is regarded as good in the above plea for integration from Barkow et al. is that it is believed to be fruitful (i.e., generative): leading to new insights, theories, or even fields. Yet there seems to be a further assumption, even if it is only implicitly made in the quote. Barkow et al. seem to assume that integration and generativity (i.e., the production of new insights, new methods, or new theories representing whole new interdisciplinary fields) are so closely connected that therefore separation cannot be fruitful. This is what I label the argument from integration.

That they entertain this argument from integration (and even should do so for their own consistency) can be deduced from the context of the quotation: the explicit enemies of their text are people like Kroeber, involved in the development or defense of what Barkow et al. call the "standard social science view," a view that ignores any evolutionary explanations of our behavior, and thus exhibits what I call a separationist strategy. Barkow et al. bring in the fruitfulness of integration to argue against Kroeber and scientists like him.

Made explicit, the argument from integration is: anthropologists should not ignore human nature in their explanations since otherwise generativity is lost. Social scientists in general should always aim at integration: they should correct their views in face of the knowledge in other fields because this secures the generativity of research (i.e., the production of novel, reliable, justified beliefs).

\footnotetext{
6I owe the term "corrective symmetry" to Steel (2004), though he uses it in slightly but philosophically decisively different ways.

${ }^{7}$ One would have to deal with reduction and the concept of a hierarchy of levels, which are intricate concepts that would lead us to far away. See Wimsatt (2007) and Brooks (forthcoming) instead.
} 
But Barkow et al. can argue against Kroeber and the like in this way only if it is indeed the case that the latter's separationist stance has failed to be generative. And this is the assumption that I will criticize. A view that claims that only integration can be generative suffers from (what I call) a synthesis bias. ${ }^{8}$ The argument from integration is biased regarding the historical cases since it disregards the actual historical fruitfulness of the separationist stance.

A similar synthesis bias might surface in the assumptions of the direct critics of evolutionary psychology. John Dupré (2010), for instance, allying himself with the developmental systems perspective, criticizes evolutionary psychologists for ignoring culture. Even though I agree with Dupré on most of his points against evolutionary psychologists, I shall develop a path between these polar positions. The argument is that it can be fruitful for both sides to ignore certain phenomena or causal factors and to thus utilize a nature/culture divide to establish a division of labor (and thus disciplinary primitives) in the explanation of what we are, think, and do.

The argument that I want to establish-the pragmatic-pluralist argument from the fruitfulness of epistemic demarcation - is that, in principle, separation (as a heuristic research strategy) can be as fruitful as integration; whether it is fruitful depends on context. Separating oneself in the sense of assuming disciplinary primitives - not in willfully accepting known inconsistencies, but in not checking for consistency-can have fruitful potential. If integration is valued because it encourages progress, then separation has to be taken as equally valuable if it encourages progress. To use an analogy: as evolutionary theory showed us that geographic isolation can be a creative factor in the evolution of species, this paper aims to show that epistemic demarcation can be a creative factor in the evolution of disciplines and theories.

\section{The argument from fruitful separation}

To argue against the synthesis bias, it is sufficient to establish that separation can be equally fruitful. Thus, one example of a separationist stance that has been fruitful is all that is needed. I will present Kroeber's above mentioned case as such an example, i.e., as a separationist stance that was epistemically fruitful.

\footnotetext{
8 I owe the idea of comparing integration and separation as values to a short piece from Gerald Holton (1978), who shows that in the history of science en gros, synthesis has often been valued more than analysis, even though both should be regarded as being of equal value since sciences need both for progress. Oppenheim \& Putnam (1958: 16) are another example for synthesis bias. They wrote that the unity of science should be a working hypothesis since it "is, as has often been remarked, fruitful in the sense of stimulating many different kinds of scientific research. By way of contrast, belief in the irreducibility of various phenomena has yet to yield a single accepted scientific theory." This claim was unjustified already in 1958.
} 
The case of Kroeber's cultural determinism

Kroeber was Franz Boas' first PhD in anthropology and the ninth in the whole US. He became famous at the beginning of the $20^{\text {th }}$ century, when anthropology emancipated itself from a museum-based profession to an academic discipline. At that time, anthropologists were not alone in maturing as a science, a process which includes: asking for money, jobs, and institutional as well as intellectual power. Psychology and the expanding field of genetics were their most prominent competitors at that time. Kroeber was very engaged in the respective disciplinary "identity politics" and developed what has been called a radical "cultural determinism." ${ }^{9}$ His case shows how - through the reconstitution of a field-defining phenomenon: culture-certain phenomena or causal factors can be made epistemically irrelevant.

Kroeber defended the identity and importance of cultural anthropology by using the biologist's own concept of heredity: he defined culture as heredity of another sort that is, at the same time, opposed to biological heredity. He moved from an analogy (culture as heredity) to a contrast: biological heredity (nature) versus cultural heredity (culture). Culture derives from previous culture, as a cell derives from previous cells, and (as we would add today) bits of DNA derive from previous bits of DNA. Since culture derives from previous culture it is autonomous from cells and biological heredity. This move helped him not only to establish the autonomy of cultural change from biological evolution, but also the identity and autonomy of those studying cultural change, which he termed (interchangeably) historians or anthropologists.

As Figure 1 nicely illustrates, there is not one evolution of organisms anymore, but three: the evolution of superorganic culture, of organic evolution, both contrasted with physical persistence (of stones, for instance, which do not reproduce and die, but persist and thus do not evolve). The evolutionary process is partitioned into three separate and autonomous processes. There are a couple of epistemic aspects of this separation of distinct evolutionary processes that need to be taken seriously:

- Kroeber partitioned one phenomenon (being human and the evolution of being human) into three distinct autonomous processed.

- He thereby established a new separate explanandum, namely culture. Culture is not explaining life or the evolution of organisms; it is to be explained, i.e., it is the new field-defining explanandum for the new specialist on stage, the cultural anthropologist.

\footnotetext{
${ }^{9}$ His case has historically been analyzed in detail in Kronfeldner (2009) and Jackson (2010).
} 
- As part of this, nature becomes a disciplinary primitive: one can safely assume it and then ignore it since it does not make a difference for the historical change in culture that the cultural anthropologist aims to explain and that is depicted in Figure 1 with its characteristic take-off (change of it without a concomitant change in nature).

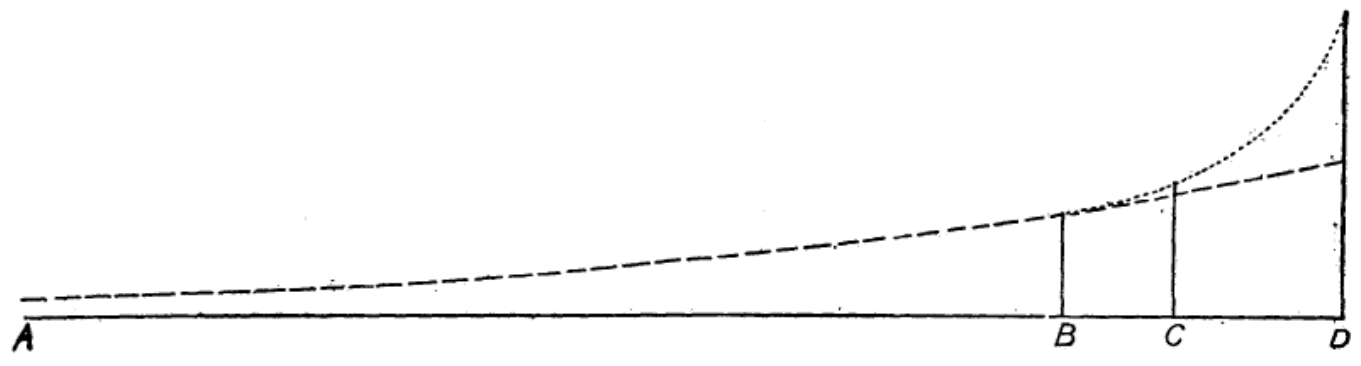

Figure 1: From Kroeber's famous paper "The superorganic" (1917: 211). It depicts three distinct and autonomously changing evolutionary processes: superorganic culture (dotted line) on the top, organic evolution (dashed line) and physical persistence (continuous line) beneath.

To think this way was far from trivial and quite fruitful to fight the scientific racism of the time. To understand why, we have to look at the importance and history of Lamarckian inheritance and the history of the concept of culture in more detail. Herbert Spencer $(1893,1894)$ famously argued for the necessity of Lamarckian inheritance to explain the evolution of musical sense and higher cognition generally. According to Spencer, there could not be a being like Mozart in Samoa, an example August Weismann (1892) used, because people in Samoa cannot have the same musical sense as people of Mozart's "kind" and "time," simply because if they do not have the same kind of music they do not have the same kinds of musical minds. Given Lamarckian inheritance, this was a valid inference. Spencer assumed that one can directly infer respective natural differences from cultural differences (and vice versa) since nature becomes culture, which becomes nature in turn, ... prohibiting the take off one sees in Kroeber's figure. In a Lamarckian picture, nature and culture are one indivisible system of inheritance and evolution.

On the basis of a Weismannian point of view, however, one could not infer racial differences from cultural differences since the two are independent, decoupled from the very first moment when the first animal managed to learn socially from another one, i.e., from the very "birth" of culture (B in the figure). Since Lamarckism is wrong, as Weismann stressed, there can be a Mozart in Samoa, i.e. it is an empirical possibility that there can be a human being in Samoa with the same cognitive capacities as the real historical Mozart. Kroeber 
used Weismann's claims to not only fight racism but to also establish the autonomy of cultural anthropology. ${ }^{10}$

Both, Weismann and Kroeber believed that only if Lamarckian inheritance is replaced with the concept of cultural inheritance is one able to maintain (a) that cultural change is historically not correlated with biological change, i.e. that one can change without the other and is autonomous in that sense. There is then also (b) no evidence to not believe in the psychic unity of humankind - if all one has is access to cultural differences and that is all one had at that time since genetic factors were still hypothetical entities only. Therefore, from Weismann's and Kroeber's perspective the unity of humankind could safely be assumed, i.e. taken as a base line on top of which culture "takes off." If so, then (c) cultural change and differences are to be explained by cultural change and differences, rather than by a shared human nature.

It is important to acknowledge that with this decoupling Kroeber did not deny that there is a shared human nature as well as individual natures (i.e., differences in nature between individual people) that are important to explain each individual's behavior. He only (c.i.) denied that individual innate differences are important for what he wanted to explain-shared culture-since they average out at the cultural (i.e., group) level, and (c.ii) stressed that the shared human nature does not make a difference for cultural differences at the group level either since culture changes and differs on the basis of a shared human nature.

As a consequence, nature is a disciplinary primitivum, a phenomenon taken for granted, on top of which culture happens. And this holds despite the fact that at the individual level of development, nature and nurture certainly interact. But the individual level (explaining behavior of humans) is not the core explanandum anymore, and the co-evolution of nature and culture, of biologically and socially inherited developmental resources, was not yet an explanandum.

Kroeber epistemically reconstituted what "culture" means, he reconstituted the explanandum in the following sense.

\footnotetext{
${ }^{10}$ Although important, I have totally left out a discussion of how further political and social dimension entered Kroeber's felt need for boundary work, i.e., how industrialization, democracy, capitalism, imperialism and the regulatory control of behavior involved in the "disciplining" of humans played a role. I did so deliberately since it would by far exceed the space available here. Useful entry points for this are Ross (2003) or Patterson (2001). One thing is important to note, though: It has often been stressed, that the Vienna Circle's rally for a unity of science had a political motivation, against the nationalism and racism of the early 20th-century Europe. Kroeber had the same political enemies but the exact opposite epistemic strategy to beat them. Thus, even if political contexts play a role, "we will not find [...] a single-valued, transhistorical function that plots assessment of unity onto a fixed political map," as Galison (1996: 8) already stated.
} 
1. "Culture" referred to traits of a group of people (playing the role of an explanandum) in the classic $19^{\text {th }}$ century evolutionist picture of anthropologists such as Edward B. Tylor, irrespective of how these traits are caused.

2. It predominantly referred to factors in development, playing a role as part of the explanans for explaining behavior in Boas' work, who reformed anthropology in many senses.

3. With Kroeber, "culture" became a system of inheritance, a new explanandum in its own right that is explained by previous culture, analogous to biological inheritance.

4. Finally, on the basis of this, culture recently became a factor in evolution (as part of the explanans in contemporary co-evolutionary theory) to explainnot behavior as such, but evolution of behavior. ${ }^{11}$

\section{How to evaluate his case}

How shall we evaluate this case in terms of epistemic fruitfulness? I introduced epistemic fruitfulness as generativity, which is regarded by Barkow et al. (and many others) as an epistemic value, something a theory should exhibit. Generativity of a perspective (or approach, theory, model, etc.) consists in the production of new insights, new methods, or new inter-field theories representing whole new interdisciplinary fields. A new insight can be positive or negative, i.e., producing new knowledge or establishing the dismissal of wrong beliefs.

(a) A new insight: Even though people defended (and still defend) scientific racism (let alone racism) on all kinds of grounds, I regard Kroeber's claim of the autonomy of culture as a historically important insight that helped to fight the false scientific racism of the early $20^{\text {th }}$ century, which was supported by the belief in the inheritance of acquired characteristics. Thus, Kroeber developed an important and fruitful thesis that blocked one argument pattern for scientific racism of that time.

(b) New field with new methods: Kroeber's analogy between culture and nature as two systems of decoupled inheritance was not used for integration but for separation: of culture from nature, and of the alleged experts studying these, i.e., cultural anthropologists on the one hand, and physical anthropologists plus

\footnotetext{
${ }^{11}$ For details on this dialectic history of the concept of culture, see Kronfeldner (2009). For more on changing the explanandum from explaining individual development of a trait to explaining differences between individuals, see Kronfeldner (2015).
} 
geneticists on the other hand. ${ }^{12}$ Kroeber, as mentioned, did not want to say that physical anthropologists or geneticists do not have a word to say on humans. He believed that science is fruitful only if each of these has a domain of its own. In the context of his time, I believe, he was right: it certainly was more fruitful at that time that each had a domain of his own in order to establish a field within science that has produced a tremendous amount of knowledge essential to understand what humans are, think, and do.

(c) Precursor of new interfield: Since Kroeber used the concept of distinct channels of inheritance, he can be considered as a precursor of contemporary dual or multiple inheritance theories studying the co-evolution of nature and culture, i.e., the evolutionary interaction of the two systems of inheritance. ${ }^{13}$ These theories go beyond Kroeber since they indeed integrate in an interactive sense what became separated in Kroeber's hands. These theories are also in and of themselves quite productive, in at least three senses: in contrast to approaches such as evolutionary psychology, they can show in a statistical manner how biologically maladaptive behavior can evolve on the basis of specific cultural transmission settings; they can also show that different modes of learning (individual learning, prestige bias, conformist bias, success bias, etc., all settings analogous to the biological mechanisms of heredity) lead to different macro-evolutionary patterns; they finally can describe the evolutionary interaction of nature and culture, e.g., how settings about legal inheritance and cultural learning influence the probability that a trait such as lactose tolerance (widespread, for instance, in Northern but not Southern Europe) can evolve. ${ }^{14}$

Kroeber ignored that nature and culture interact as factors in the evolution of humans since for him culture was first and foremost an explanandum. In contemporary co-evolutionary theory, culture takes on a different epistemic role: it is regarded as part of what explains evolution (a part of the explanans), rather than as a system of inheritance that is explained (explanandum). Kroeber was working at a different time and had to first separate what later became kinds of causes for a more general explanandum (co-evolution). Culture and nature thus have become-with but also beyond Kroeber-not just separate systems of inheritance but special kinds of causal factors in the evolution of human traits, be these traits physical or mental. In his own time, Kroeber regarded nature and culture not just as separate but he ignored any possible

\footnotetext{
12 With psychologist and sociologist also studying something different. For the separation of sociology and anthropology see the paper that Kroeber wrote together with Talcott Parsons (1958).

${ }^{13}$ See Boyd \& Richerson (1985) as an instance of the first, and Jablonka \& Lamb (2005) as an instance of the second. For comparison and general analysis, see Lewens (2015).

${ }^{14}$ For more on the productivity of multiple inheritance theories, see Kronfeldner (2013).
} 
interaction of them on a longer time scale, too focused on fighting the enemy of his time: scientific racism, which did not allow for culture to change independently of nature. That Kroeber's perspective is today too radical does not conflict with the claim that his separationist stance was quintessential for the historical development described in this paper and justified given the generativity it exhibited.

\section{Summary of the case and two arguments established}

To summarize: Kroeber defended the place of cultural anthropology against the social and political hegemony of racist hereditarianism and the scientific force of the new genetics. He crossed the boundary between anthropology and biology and used Weismann's theory of heredity, at a time when both disciplines were expanding their scientific and institutional setting. The goal of the boundary crossing was however to make the boundary 'fences' between the two disciplines even higher. He did this in order to establish a clear specialization, a differentiation, i.e., a clear division of labor-divide and conquer-between anthropology and biology, and between physical anthropology and cultural anthropology. When disciplines emerge, it is unlikely that their representatives are open-minded, for pragmatic reasons: they have to establish themselves first and secure a place in the midst of other disciplines. They have to appropriate phenomena.

The case shows that, as research strategies, integration and separation can both lead to fruitful scientific results. I named three such results for Kroeber's case of separating culture and nature as two different systems of inheritance. The separationist stance has been fruitful, since:

a) it helped to block one detrimental argumentation pattern for racism in early 20th-century,

b) it helped stabilize a young and at that time still fragile but productive subdiscipline, namely cultural anthropology,

c) it was a historical precondition for contemporary co-evolutionary theories, productive approaches to specific problems regarding how culture and nature interact on the evolutionary level.

To conclude: There are then cases where it is more useful, in the service of scientific productivity, to batten down the hatches of one's scientific horizonfor a while at least. Sometimes it is fruitful to separate oneself: to ignore, for specific goals, that everything in reality hangs together in complex ways and that therefore nothing is autonomous. 
The argument from fruitful separation is a general one (applying to the relationship between all kinds of phenomena and fields attached to phenomena), but it entails a more specific argument, specific to the relationship between nature and culture. The divide between nature and culture can be an epistemic mean for fruitful research in that it provides disciplinary primitives that allow for fruitful separation of kinds of explanations typical of a discipline or field. It is thus epistemically justified even though in the world everything hangs together and is on a par.

\section{5. "It takes two to tango" and integration as regulative ideal}

Over the long run, it certainly takes two to tango, i.e., separation and integration must be in a dialectic balance with each other in order to get ahead in a specific field, i.e., to reach an "oscillatory progress" (Holton 2010: 249). Or, as Hans-Jörg Rheinberger (1997: 253) wrote: "Fragmentation, aiming at simplicity, finally creates complexity" - a managable, palpable complexity instead of an undifferentiated one. Those who draw distinctions first and connect later, see more.

If separation and integration are in the long run both necessary for the generativity of science, they should have in principle equal value. But the philosophical literature by and large seems to still place a higher priority on integration (or "unification" as some still prefer to call it). It is a higher, if not the ultimate "regulative ideal" (Kitcher 1999) of science, a higher-level norm. As a regulative ideal, it is, according to Philip Kitcher (1999: 342), "good where we can get it, but not to be imposed willy-nilly." There are contexts where we should not apply it. Richard Burian (1993) defended a similar nuanced position, taking separation as transiently useful in certain contexts. He writes: "It is a matter of judgment when to take the norm seriously. ... But this in no way undercuts the legitimacy of unification as a generally applicable higher-level norm" (Burian 1993: 314).

Kitcher and Burian are on the right track but miss the crucial point nonetheless. The context in which separation or integration can be useful includes a specific way of understanding the phenomenon at issue. Burian thus formulates the higher-level norm also as a conditional: "when work in different disciplines bears on a given problem, their practices, terminologies, and standards for evaluation of experimental evidence must be brought into accord with respect to the matter at hand for it to count as satisfactorily solved" (Burian 1993: 313; emphasis added). Well, problems are not simply "given." They are reconstituted, as in Kroeber's case, so that there is a functioning 
division of labor. Kroeber reconstituted culture in a way so that it allows the autonomy of cultural anthropology.

Burian in principle recognizes this option (and he seems to be the only one in the literature on the value of unity or integration): problems and phenomena can be reconstituted so that there is no need to integrate knowledge from diverse disciplines. "Ultimately," Burian writes, only one of the following options has to be fulfilled in an interdisciplinary encounter: "(1) achieve coherence between different scientific descriptions of the phenomena of concern and also between those descriptions and any theoretical explanations of those phenomena, or (2) transform the problem of concern so as to remove the obligation to take into account one or more of the competing descriptions or theories" (Burian 1993: 302-3). ${ }^{15}$ Even though he thus admits that separation and integration are on a par, two distinct ultimate research strategies, he regards separation as a makeshift: a good strategy if things get too complex. ${ }^{16}$ Unity stays the regulative ideal. This ignores that separation can be permanent without preventing local integration. Local integration can consist in the integration of knowledge for a concrete problem or stabilize itself as a new interfield (to solve a specific type of problem). To consider separation and integration as of equal value means allowing for a permanent separation without denying that at certain points there should be local integration. ${ }^{17}$

Stressing that separation is permanent does not imply that priority is given to separation. Giving priority to separation would involve claiming that only if there is no division-of-labor that allows one to reconstitute a phenomenon, should one look for integration. No such claim has been defended here. The differentiation of disciplines historically correlates with a tremendous increase in knowledge. This could be taken as evidence that separation is more important than integration. Yet, there is evidence in the other direction too: As a regulative ideal separation (with integration as makeshift) would lead to an indefinite proliferation of problems and would lower the probability that errors are found via integration (thanks to its corrective force). Science, after all, is a systematic knowledge production endeavor and is robust thanks to its networklike structure. In a network, separation and integration are of equal value.

\footnotetext{
${ }^{15}$ Burian even gives a similar example: "One way of transforming a problem is by dividing it into strongly separate problems. For example, the rejection of Haeckel's biogenetic law facilitated just such a separation between the problem of determining the causes of evolution and the problem of establishing phylogenies." (Burian 1993: 303)

16 The same holds for Kitcher's "modest unificationism." Kitcher (1999) admits that there is no "fixed totality of questions," but does not consider the consequences of this for separation as equally valuable. Van der Steen (1993) also deplores a synthesis bias. I agree with Steen on the diagnoses, but not with the therapy.

${ }^{17}$ Closest to my account is thus Mitchell $(2003,2009)$.
} 
Kroeber (1948: 260) postulated a similar network structure for culture, and depicted it, as in Figure 2: as a tree-at that time the most conventional depiction of differentiating structures. He described it as the "tree of [the knowledge of good and evil-that is, of human] culture" and wrote of its form: "There is a constant branching-out, but the branches also grow together again, wholly or partially, all the time. Culture diverges, but it syncretizes and anastomoses too" (ibid.). Science too is a form of culture that evolves as a system of inheritance of knowledge with differentiation and local integration.

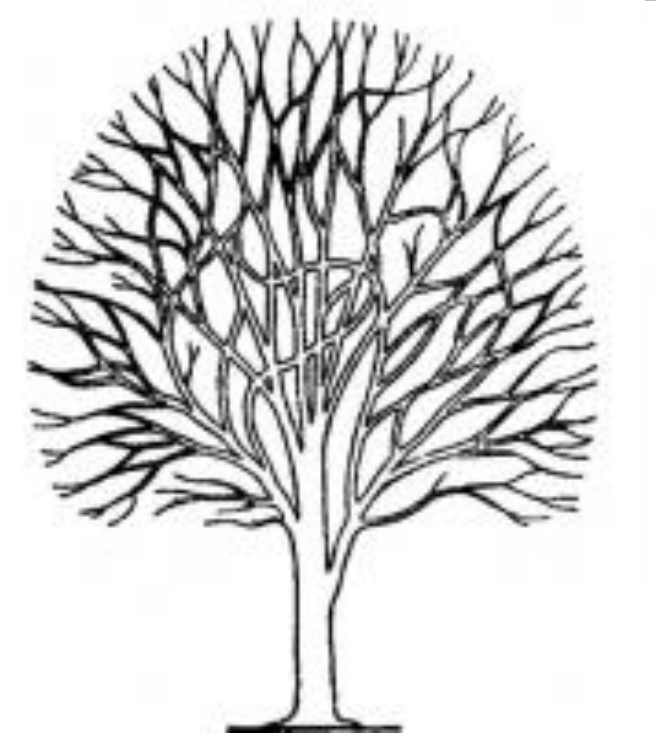

Figure 2: Kroeber's tree of knowledge (from Kroeber 1948: 260).

\section{Conclusion}

As long as separation is paired with later integration, it can result in fruitful scientific results since (if successful) it elucidates phenomena and is in that sense of epistemic value. The separationist strategy is a piecemeal heuristic but a fruitful one, as is the integrationist strategy. We can thus consider it as a good thing that there are different kinds of experts devoted to their "own" kind of causes, so that there is partial knowledge (from studying one factor in isolation, i.e., while the others are ignored) that can later be integrated. In the long run, science needs both separation of disciplines like evolutionary biology, psychology, cultural anthropology, philosophy etc., and it needs integration.

\section{Acknowledgments}

I would like to thank the Department of Philosophy at Bielefeld University, the Center for Philosophy of Science at the University of Pittsburgh, and the Fishbein Center for the History of Science and Medicine at the University of Chicago for supporting my research during the time when the research that is 
at the foundation of this paper was done. In particular, I would like to thank Hanno Birken-Bertsch, Martin Carrier, Heather Douglas, John Jackson, Richard Joyce, Maureen O`Malley, Sandra Mitchell, Alexander Reutlinger, Betty Smocovitis, Kyle Stanford, David Stump, and the audiences at the 2015 Meeting of the Nordic Network for Philosophy of Science and the 2015 Human nature course at the CEU for helpful discussions related to this paper.

\section{References}

Barkow, J., Cosmides, L., \& Tooby, J. 1992. The Adapted Mind: Evolutionary Psychology and the Generation of Culture (Oxford University Press).

Birken-Bertsch, H. 2013. "Zur zritik anthropologischer wenden im ausgang von Joachim Ritter." In A. Hügli, A. Horn, A. Kottmann, C. Steiner, S. Tietz, F. Wüstholz, \& A. Wunder (eds.), Die Anthropologische Wende (vol. 72). (Schwabe) 315-327.

Boyd, R., \& Richerson, P. 1985. Culture and the Evolutionary Process (University of Chicago Press).

Brooks, D. 2014. The Concept of Levels of Organization in Biology. Dissertation. Bielefeld.

Burian, R. 1993. "Unification and coherence as methodological objectives in the biological sciences." Biology and Philosophy 8: 301-318.

Dupré, J. 2010. "Causality and human nature in the social sciences." Kölner Zeitschrift Für Soziologie, Sonderheft 50: 507-525.

Galison, P., \& Stump, D. (eds.). 1996. The Disunity of Science: Boundaries, Contexts, and Power (Stanford University Press).

Geertz, C. 1973. "The impact of the concept of culture on the concept of man." In C. Geertz, The Interpretation of Cultures: Selected Essays (Basic Books) 33-54.

Holton, G. 1978. "Analysis and synthesis as methodological themata." In G. Holton, The Scientific Imagination: Case Studies (Cambridge University Press) 111-151.

Jablonka, E., \& Lamb, M. 2005. Evolution in Four Dimensions: Genetic, Epigenetic, Behavioral and Symbolic Variation in the History of Life (MIT Press).

Jackson, J. 2010. "Definitional argument in evolutionary psychology and cultural anthropology." Science in Context 23: 121-150.

James, W. 1897. The Will to Believe, and Other Essays in Popular Philosophy (Longmans, Green, and Co.).

Kitcher, P. 1999. "Unification as a regulative ideal." Perspectives on Science 7: 337-348.

Kroeber, A. 1917. “The superorganic.” American Anthropologist 19: 163-213.

Kroeber, A. 1948. Anthropology: Race, Language, Culture, Psychology, Prehistory (2nd ed.). (Harcourt, Brace).

Kroeber, A., \& Parsons, T. 1958. "The concept of culture and of social system." American Sociological Review 23: 582-583.

Kronfeldner, M. 2009. "If there is nothing beyond the organic... : Heredity and culture at the boundaries of anthropology in the work of Alfred L. Kroeber." NTM: Journal of the History of Science, Technology and Medicine 17: 107-133. 
Kronfeldner, M. 2010. “Won't you please unite? Darwinism, cultural evolution and kinds of synthesis." In E. Barahona, H.-J. Rheinberger (eds.), The Hereditary Hourglass: Genetics and Epigenetics, 1868-2000. (Max Planck Insititute for the History of Science) 111-125.

Kronfeldner, M. 2013. "Die epistemische fragmentierung des menschen: Wie der mensch zwischen natur und kultur verschwindet." In A. Hügli, A. Horn, A. Kottmann, C. Steiner, S. Tietz, F. Wüstholz, \& A. Wunder (eds.), Die Anthropologische Wende (vol. 72). (Schwabe) 287-313

Kronfeldner, M. 2015. "Reconstituting phenomena." In U. Mäki, I. Votsis, S. Ruphy, \& G. Schurz (eds.), Recent Developments in the Philosophy of Science: EPSA13 Helsinki (Springer) 169-182.

Kronfeldner, M. Forthcoming. "Divide and conquer: The authority of nature and why we disagree about human nature." In T. Lewens \& E. Hannon (eds.) Why we Disagree About Human Nature (Oxford University Press).

Lewens, T. 2015. Cultural Evolution: Conceptual Challenges (Oxford University Press).

Logan, C. \& Johnston, T. 2007. "Synthesis and separation in the history of 'nature' and 'nurture.'" Developmental Psychobiology 49: 758-769.

Mäki, U. 2014. "Scientific imperialism: Difficulties in definition, identification, and assessment." International Studies in the Philosophy of Science 27: 325-339.

Midgley, M. 1995. Beast and Man: The Roots of Human Nature (Routledge).

Mitchell, S. 2003. Biological Complexity and Integrative Pluralism (Cambridge University Press).

Mühlmann, W. 1986. Geschichte der Anthropologie (Aula-Verlag).

Oppenheim, P. \& Putnam, H. 1958. "Unity of science as a working hypothesis." In H. Feigl (ed.), Concepts, Theories and the Mind-Body Problem (University of Minnesota Press) 3-36.

Patterson, T. 2001. A Social History of Anthropology in the United States (Berg).

Ross, D. 2003. "Changing contours of the social science disciplines." In T. Porter \& D. Ross (eds.), The Modern Social Sciences (Cambridge University Press) 205-237.

Spencer, H. 1893. “The inadequacy of 'natural selection,' I and II." Contemporary Review 63: 153-166, 439-456.

Spencer, H. 1894. “Weismannism once more." Contemporary Review 63: 592-608.

Steel, D. 2004. "Can a reductionist be a pluralist?" Biology and Philosophy 19: 5573.

Van Der Steen, W. 1993. "Towards disciplinary disintegration in biology." Biology and Philosophy 8: 259-275.

Wimsatt, W. 2007. Re-Engineering Philosophy for Limited Beings: Piecewise Approximations to Reality (Harvard University Press).

Weismann, A. (1892). Gedanken über Musik bei Thieren und beim Menschen. In A. Weismann. Aufsätze über Vererbung und verwandte biologische Fragen (pp. 587-637). Jena: Gustav Fischer. 